\title{
Investigando a compreensão de representações diagramáticas utilizadas em análise da tarefa: um estudo comparativo entre modelagem hierárquica e seqüencial
}

\author{
Investigating the comprehension of diagrammatic representations used in task \\ analysis: a comparative study between hierarchical and sequential modeling
}

\author{
Stephania Padovani, Kelli Cristine Assis da Silva Smythe
}

Representação gráfica, análise da tarefa, experimento

\begin{abstract}
O presente estudo tem como objetivo verificar a facilidade de produção e compreensão de representações diagramáticas empregadas pelos métodos de análise da tarefa por estudantes de design. Visando atingir tal propósito, realizou-se um levantamento de representações gráficas de decomposição de tarefa na literatura especializada, seguido de estudo experimental comparando duas formas de decomposição específicas: diagrama hierárquico e diagrama seqüencial de decomposição da tarefa. Os resultados demonstraram que a maioria dos participantes preferiu o diagrama seqüencial em praticamente todos os critérios de avaliação empregados. Entretanto, os participantes concluíram que ambos os diagramas seriam úteis durante a análise da tarefa, sendo que a escolha do diagrama dependeria do desdobramento desejado pelo analista após a decomposição da tarefa.
\end{abstract}

Graphic representation, task analysis, experiment

This study aims to assess ease of production and comprehension of diagrammatic representations employed in task analysis methods by design students. In order to achieve such purpose, a literature survey of graphic representations was carried out, which was followed by an experimental study comparing two different task description formats: hierarchical diagram and sequential flowchart. The results demonstrated that the majority of participants preferred the sequential diagram in virtually all evaluation criteria. However, participants also concluded that both diagrams would be useful during task analysis, being the choice dependent upon the extension desired by the analyst following the task analysis.

\section{Introdução}

Durante o processo de design de sistemas de informação, estes necessitam ser representados graficamente para que possam ser traduzidos de seus aspectos conceituais para seus aspectos tangíveis. Neste contexto, as representações gráficas podem ser consideradas um elo básico de ligação e diálogo entre os membros dos grupos de projeto, tanto nas atividades de criação, quanto nas de avaliação e implementação.

Representações gráficas são reconhecidamente importantes em processos de solução de problemas (como é o caso do processo de design). Norman (1993), por exemplo, afirma que essas representações funcionam como artefatos cognitivos, livrando a memória de curta duração para raciocinar sobre o problema em questão, uma vez que os aspectos descritivos do problema já teriam sido externalizados na representação. Matlin (2004) corrobora essa afirmação ao incluir a geração de representações como parte do processo de solução de problemas, entre o primeiro estágio (seleção e atenção a informações relevantes) e o último estágio (seleção de estratégia de solução).

Durante o desenvolvimento do projeto, as representações gráficas utilizadas por designers e colaboradores variam em seu nível de complexidade, fidelidade e abstração. No início do processo, por exemplo, gráficos, diagramas e tabelas são empregados para demonstrar os resultados do levantamento de dados de pesquisa de mercado, pesquisa com usuários ou consultores especialistas. $\mathrm{Na}$ fase de conceituação, diagramas, mapas conceituais e sketches são utilizados para sintetizar requisitos e produzir as primeiras idéias. Em seguida, na fase de geração de alternativas, utilizam-se a princípio sketches e então representações gráficas de 
maior fidelidade, em geral produzidas a partir de programas gráficos. Na fase de detalhamento do projeto, uma série de representações detalhadas incluindo todos os atributos gráficos do sistema, além de protótipos funcionais são gerados. Por fim, na fase final de validação, utilizam-se representações similares às da fase inicial de análise para tabular e apresentar os resultados dos testes realizados. Predominam, portanto, nesta fase final, gráficos e tabelas.

Neste trabalho enfocamos especificamente representações gráficas utilizadas no método de análise da tarefa. Este método é empregado nos estágios iniciais do processo de design para entender a tarefa a ser executada pelos usuários do sistema, além de seus requisitos funcionais e informacionais. $\mathrm{Na}$ fase de decomposição da tarefa, especificamente, os diagramas gerados representam as relações (e.g., seqüencial, alternativa, concomitante) entre as atividades envolvidas na execução da tarefa, podendo também, posteriormente, agregar requisitos, condições de realização e resultados de tais atividades (vide figura 01).

Figura 1: Exemplo de parte de um diagrama representando atividades, fontes de informação e requisitos informacionais associados usado no método TRIA - Task-related information analysis (fonte: Sutcliffe, 1997)

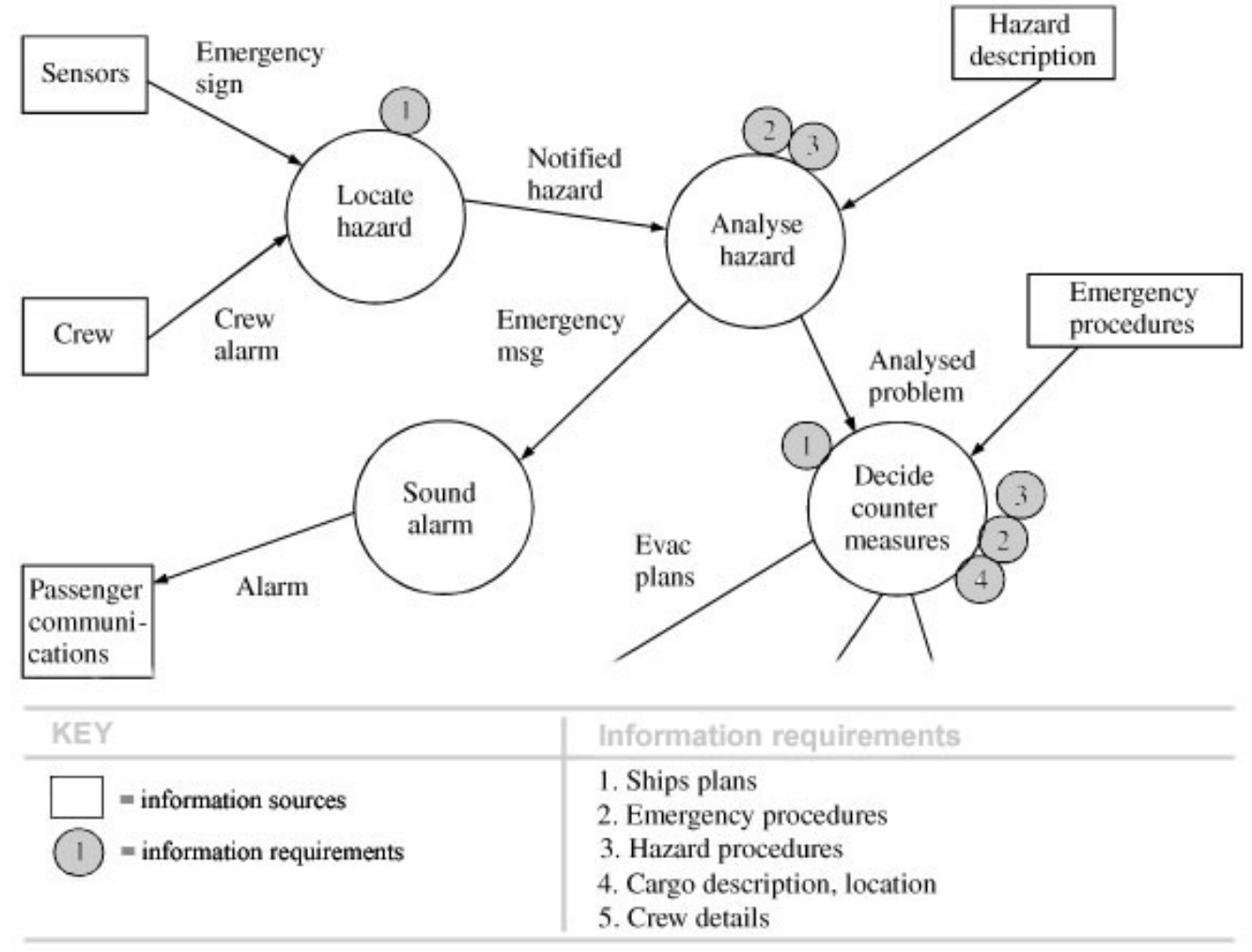

Conforme Valente e Santos (2004), para que a comunicação intermediada por representações gráficas seja eficiente, a representação deve ser precisa, ou seja, deve representar de maneira clara, inequívoca e com exatidão o sistema em desenvolvimento. Claramente, esta não é a situação unânime quando se trata de representações diagramáticas utilizadas em análise da tarefa. Apesar de sua potencial utilidade, as representações gráficas de análise da tarefa se encontram entre as causas das principais dificuldades na utilização do método por desenvolvedores não especialistas em Ergonomia ou áreas afins que lidam com modelagem de sistemas de maneira mais abstrata. Essas dificuldades variam desde o processo de modelagem (ARNOWITZ et al., 2000), passando pela sincronização da visualização da hierarquia de tarefas com as representações textuais da mesma informação (STUART \& PENN, 2004), até a compreensibilidade dos diagramas resultantes (DAABAJ, 2000).

Diante desta problemática, o presente estudo tem como objetivo verificar a facilidade de produção e compreensão de representações diagramáticas empregadas pelos métodos de análise da tarefa por estudantes de design (os quais podem ser considerados um grupo representativo de desenvolvedores não especialistas). Visando atingir tal propósito, realizou-se um levantamento das representações gráficas de decomposição de tarefa propostas por diferentes autores, seguido de estudo experimental comparando duas formas de decomposição específicas: diagrama hierárquico e diagrama seqüencial de decomposição da tarefa. 


\section{Representações gráficas utilizadas em análise da tarefa}

Durante o processo de aplicação do método de análise da tarefa, uma série de representações gráficas é utilizada. Tais representações variam em formato e complexidade, dependendo da fase do processo a que se destinam. No quadro 01, apresentamos uma síntese das principais representações utilizadas no método de análise da tarefa, juntamente com suas funções. Nesta pesquisa, enfocamos especificamente as representações gráficas utilizadas na fase de decomposição da tarefa, as quais têm como objetivo fornecer uma visão pormenorizada da estrutura da tarefa com objetivos, atividades ou ações que compõem a tarefa.

Quadro 1: Síntese das funções das representações gráficas em cada fase da análise da tarefa (Padovani \& Smythe, 2009)

\begin{tabular}{l|ll}
\hline Fase do método & Função da representação & Exemplos de representação \\
\hline $\begin{array}{l}\text { descrição da } \\
\text { tarefa }\end{array}$ & $\begin{array}{l}\text { sintetizar informações } \\
\text { organizacionais e operacionais da } \\
\text { tarefa }\end{array}$ & ilustrações, tabelas, gráficos \\
\hline $\begin{array}{l}\text { decomposição da } \\
\text { tarefa }\end{array}$ & $\begin{array}{l}\text { fornecer uma visão pormenorizada } \\
\text { da estrutura da tarefa com objetivos, } \\
\text { atividades ou ações que a compõem }\end{array}$ & $\begin{array}{l}\text { diagramas hierárquicos, } \\
\text { seqüenciais, tabelas }\end{array}$ \\
\hline análise da tarefa & $\begin{array}{l}\text { estimar ou verificar relações (e.g., } \\
\text { seqüência, criticalidade) entre } \\
\text { variáveis específicas da tarefa (e.g., } \\
\text { erros, acionamentos) }\end{array}$ & $\begin{array}{l}\text { redes de intensidade de fluxo, } \\
\text { gráficos de demandas, cartas de- } \\
\text { paratrizes de erro }\end{array}$ \\
\hline $\begin{array}{l}\text { síntese e } \\
\text { aplicação dos } \\
\text { dados da tarefa }\end{array}$ & $\begin{array}{l}\text { resumir os requisitos gerados pela } \\
\text { análise da tarefa a serem aplicados } \\
\text { no projeto }\end{array}$ & $\begin{array}{l}\text { listas textuais, tabelas, mapas } \\
\text { conceituais }\end{array}$ \\
\hline
\end{tabular}

O processo de geração de representações gráficas de decomposição da tarefa é bastante complexo e detalhista (vide figura 2 para entender o posicionamento deste estágio no processo de aplicação do método de análise da tarefa). Inicialmente, é necessário que o analista realize uma coleta de dados acerca da tarefa, a qual pode ocorrer utilizando-se observação direta, entrevista, verbalização ou outra técnica de inquirição contextual. Após a coleta de dados, estes são compilados em uma descrição da tarefa, a qual pode incluir aspectos organizacionais (quando a abordagem é mais macro) ou aspectos somente operacionais (quando a abordagem é mais micro, focada exclusivamente na interação entre o usuário e o sistema). De posse dessas informações, passa-se ao estágio de decomposição da tarefa. Antes que a tarefa seja decomposta é necessário decidir o nível de granularidade e/ou de abstração a ser empregado. A mesma tarefa pode ser decomposta de modo mais abstrato (considerando-se apenas metas e sub-metas, sem incluir os comandos e ferramentas utilizados para realiza-la) ou de modo mais concreto, indicando todas as atividades e ações específicas, assim como os comandos utilizados para executa-la. Decidido o nível de granularidade ou abstração, decompõe-se a tarefa em unidades, para na seqüência estabelecer as relações entre essas unidades (e.g., seqüencial, concomitante, alternativa). Somente após todos esses estágios, passa-se à produção da representação gráfica de decomposição da tarefa propriamente dita. Nesta fase, deve-se escolher uma modalidade de representação (e.g., diagrama seqüencial, diagrama hierárquico, diagrama híbrido, tabela) e produzir a representação de acordo com suas regras e notações específicas. Cumpre ressaltar que em vários dos estágios relatados anteriormente podem e devem ocorrer iterações, ou seja, o analista deve entrar em contato novamente com o usuário que relatou ou demonstrou a realização da tarefa para conferir se a representação gráfica é fiel à realidade.

Analistas mais experientes costumam optar por produzir rascunhos de fluxogramas seqüenciais ou diagramas hierárquicos de decomposição da tarefa enquanto ouvem o depoimento do usuário ou o observam realizando a tarefa, simplificando bastante o processo de produção de representações descrito anteriormente. Em contraste, desenvolvedores não especialistas em Ergonomia ou Análise de Sistemas, por exemplo, geralmente optam por produzir descrições textuais e listas de atividades antes de partir para a construção da representação gráfica final. 
Figura 2: Posicionamento da fase de decomposição da tarefa dentro do processo de análise da tarefa
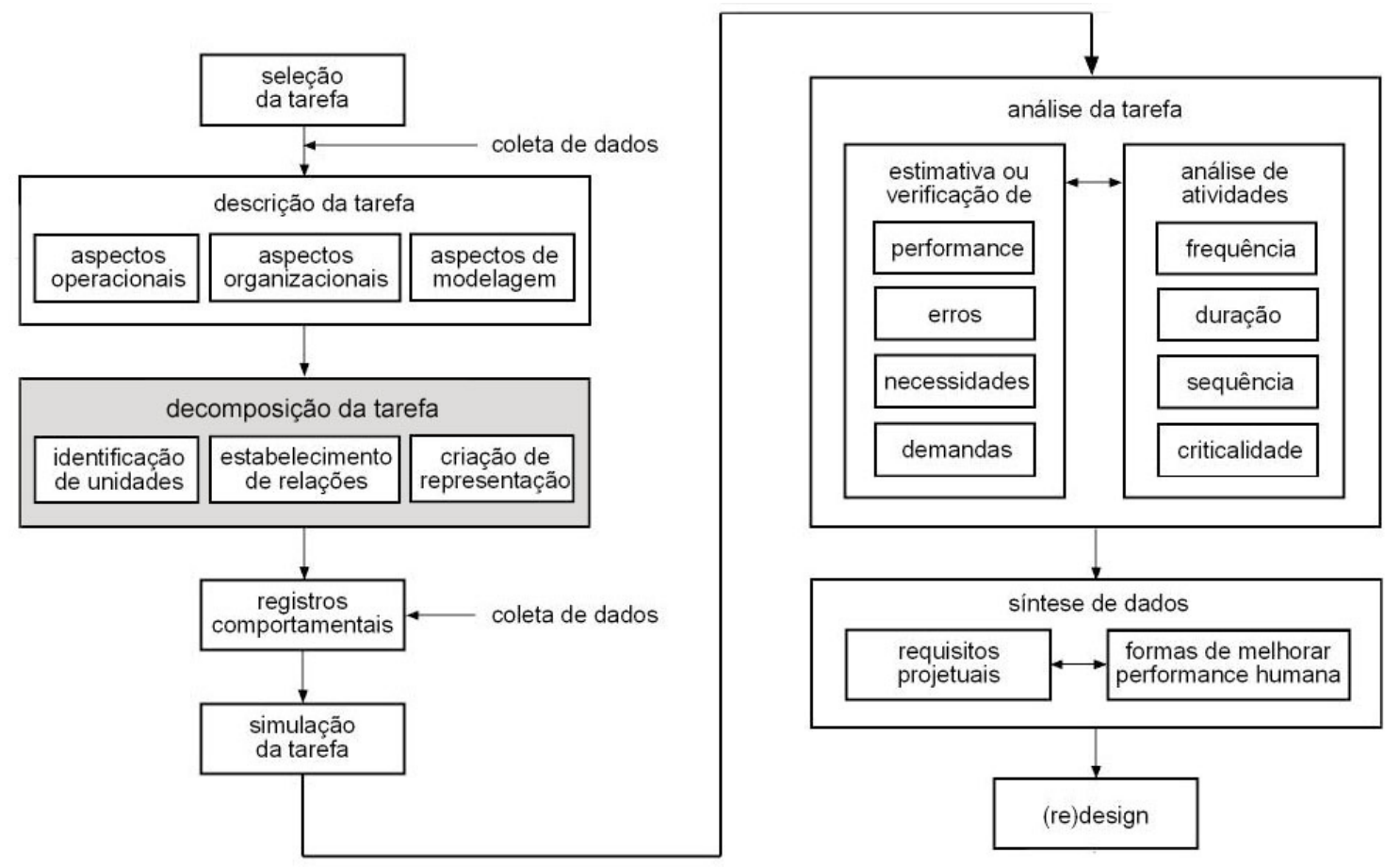

\section{Modalidades de decomposição da tarefa}

Conforme mencionado anteriormente, a mesma tarefa pode ser decomposta utilizando-se diferentes alternativas de representação gráfica. Em levantamento realizado para esta pesquisa na literatura de Ergonomia e Usabilidade de Sistemas identificaram-se 32 versões para o método de análise da tarefa. Nestes métodos, as modalidades de decomposição da tarefa identificadas foram: (a) seqüencial, (b) hierárquica, (c) tabular. A seguir, explanamos e ilustramos como tarefas podem ser representadas em cada uma dessas modalidades.

\section{Decomposição seqüencial}

Nesta forma de decomposição, a tarefa pode ser desmembrada em sub-tarefas mais globais ou em atividades bastante específicas, as quais são posicionadas exatamente na ordem em que ocorrem. Alguns autores optam por utilizar elementos gráficos mais informais e notação menos rígida, enquanto outros empregam codificações para diferenciar atividades, tomadas de decisão, relação entre atividades e continuidade da tarefa.

Em ACTA (Applied Cognitive Task Analysis - MILITELLO \& HUTTON, 1998), por exemplo, os autores propõem que a tarefa seja decomposta em sub-tarefas bastante gerais, gerando um diagrama seqüencial incluindo entre três e seis estágios. O objetivo do diagrama é, portanto, fornecer uma versão geral da tarefa para, posteriormente, identificar sub-tarefas que envolvem demandas cognitivas. As sub-tarefas aparecem em contêineres elípticos conectados por intermédio de setas para indicar a direção de leitura. Não se utiliza nenhuma notação específica ou codificação gráfica para diferenciar as sub-tarefas entre si (vide figura 3 ).

Figura 3: Exemplo de diagrama seqüencial de decomposição da tarefa de envio de mensagem por email com sub-tarefas gerais (construído com base nas especificações de Militello \& Hutton, 1998)

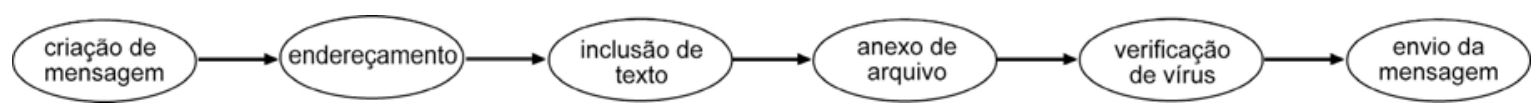


Em contraste, Moraes e Mont'Alvão (1998), por exemplo, propõem que a tarefa seja decomposta em atividades bastante específicas, as quais chegam ao ponto de incluir os artefatos utilizados para executá-las. O diagrama é construído utilizando-se contêineres retangulares para as atividades e losangos para as tomadas de decisão, ambos conectados por intermédio de setas (para indicar a ordem de leitura), conectores para explicitar relação de alternância (ou) e concomitância (e), numeração para as atividades, símbolos específicos para indicar continuidade do fluxograma, além de rótulos de início e fim da tarefa (vide figura 4).

Figura 4: Exemplo de diagrama seqüencial de decomposição da tarefa de envio de mensagem por email com atividades específicas (construído com base nas especificações de Moraes \& Mont’Alvão, 1998)

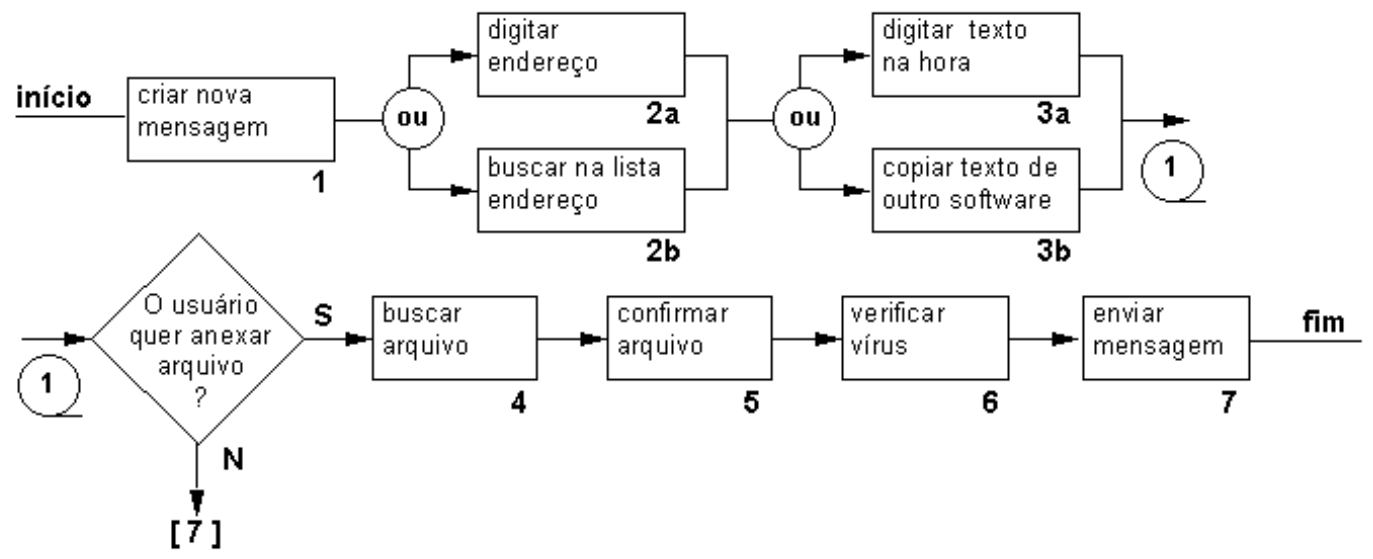

\section{Decomposição hierárquica}

Nesta forma de decomposição, identifica-se primeiramente a meta da tarefa do usuário, decompõe-se a mesma em sub-metas e então em atividades mais específicas. Após a decomposição, utilizam-se planos para mostrar como as atividades estão relacionadas.

A modalidade HTA (Hierarchical Task Analysis - SHEPHERD, 2001), por exemplo, tem como objetivo examinar metas na realização de tarefas pelo processo de descrição das mesmas utilizando sub-metas e planos. O diagrama resultante apresenta uma hierarquia inter-relacionada de metas, operações e planos. Inicia-se com a meta a ser explorada e a cada bifurcação do diagrama questiona-se: que operações (ou sub-metas) são necessárias para cumprir a meta $x$ ? Em seguida as operações (ou sub-metas) de mesmo nível hierárquico são organizadas por intermédio de plano). As operações que não mais necessitam de decomposição recebem uma marcação com uma linha espessa. (vide figura 5)

Figura 5: Exemplo de diagrama hierárquico de decomposição da tarefa de envio de mensagem por email (construído com base nas especificações de Shepherd, 2001)

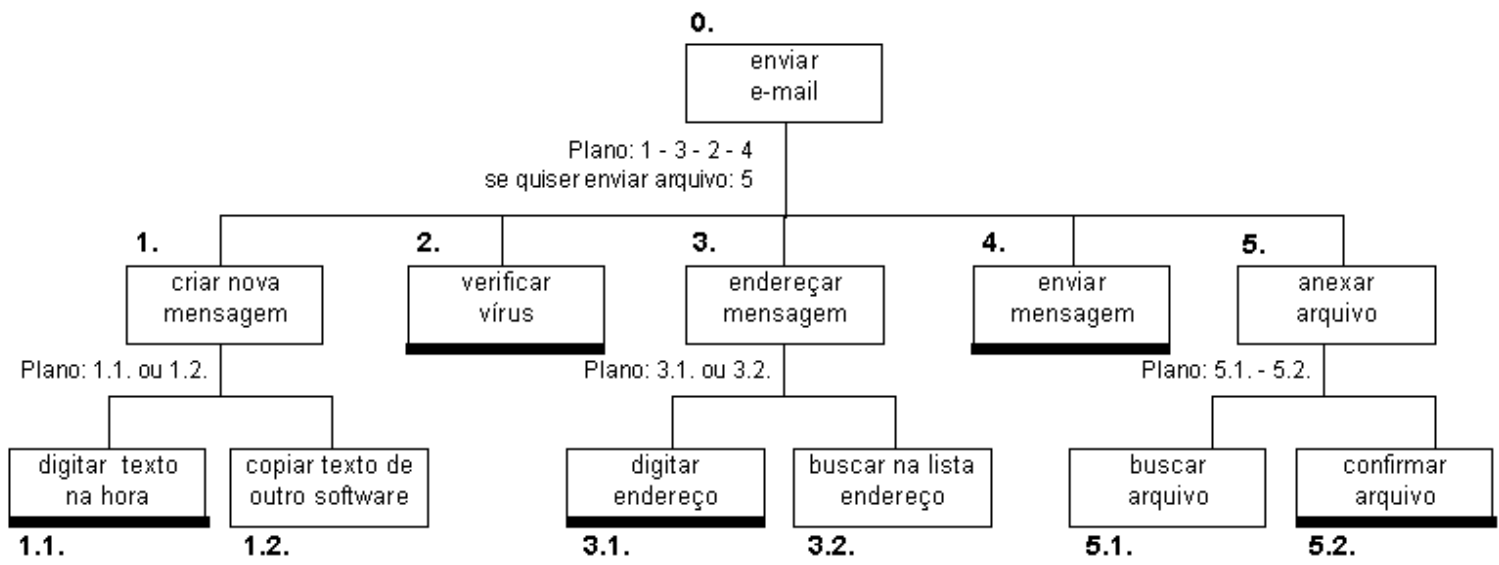


O diagrama hierárquico de decomposição da tarefa pode ser uniformizado, utilizando-se uma classificação padronizada para todas as atividades do último nível hierárquico. De forma similar, os planos passam a utilizar códigos seqüenciadores específicos. Esses procedimentos fazem parte do esquema SGT (sub-goal template) proposto por Richardson et al., (1998). Os quadros 2 e 3 apresentam as duas classificações utilizadas no esquema SGT.

Quadro 2: Classificação das operações de último nível hierárquico em HTA (conforme Richardson et al., (1998)

\begin{tabular}{l|l}
\hline Grupo & Elementos SGT \\
\hline \multirow{4}{*}{ Ação } & A1 | Preparar equipamento \\
& A2 | Ativar \\
& A3 | Ajustar \\
& A4 | Desativar \\
\hline \multirow{4}{*}{ Comunicação } & C1 | Ler \\
& C2 | Escrever \\
& C3 | Aguardar instrução \\
& C4 | Receber instrução \\
& C5 | Instruir ou enviar dados \\
& C6 | Lembrar \\
\hline \multirow{4}{*}{ Monitoramento } & C7 | Recuperar informação \\
& M1 | Monitorar para detector desvio \\
& M2 | Monitorar para antecipar mudança \\
& M3 | Monitorar freqüência de mudança \\
& M4 | Inspecionar equipamento \\
\hline \multirow{4}{*}{ Tomada de decisão } & D1 | Diagnosticar problema \\
& D2 | Planejar ajustes \\
& D3 | Localizar origem de problema \\
& D4 | Julgar ajustes \\
\hline
\end{tabular}

Quadro 3: Classificação dos elementos seqüenciadores em planos de HTA (conforme Richardson et al., (1998)

\begin{tabular}{l|l}
\hline Código & Elemento sequenciador \\
\hline S1 & Procedimento fixo: então faça $X$ \\
\hline S2 & Escolha: se $Z$, então faça $X$, se não $Z$, então faça $Y$ \\
\hline S3 & Paralelo: faça concomitantemente $X$ e $Y$ \\
\hline S4 & Seqüência opcional: faça em qualquer ordem $X$ e $Y$ \\
\hline
\end{tabular}

Aplicando-se as classificações propostas por Richardson et at., (1998), o diagrama HTA da figura 5 receberia as seguintes modificações (vide figura 6).

Figura 6: Diagrama hierárquico de decomposição da tarefa de envio de mensagem por email com classificações do esquema SGT (construído com base nas especificações de Richardson et al., 1998)

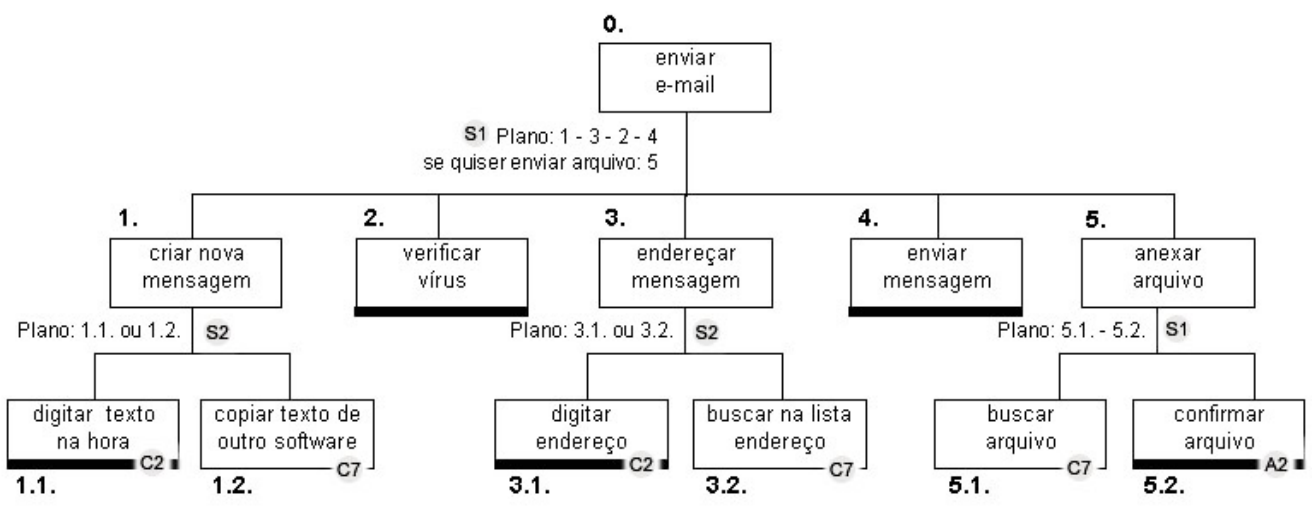




\section{Decomposição tabular}

A decomposição tabular da tarefa também aparece na literatura com a denominação de análise hierárquica da tarefa em formato tabular. Conforme Kirwan \& Ainsworth (1993), o formato tabular representa exatamente as mesmas informações que um diagrama HTA, mas possui os benefícios de não restringir o espaço disponível ao analista pra expressar os planos, operações ou mesmo notas adicionais para melhoria de performance. $\mathrm{Na}$ tabela 1, apresenta-se a mesma tarefa de enviar e-mail, decomposta hierarquicamente e representada em formato tabular.

Tabela 1: Exemplo de análise hierárquica da tarefa em formato tabular (conforme especificações de Shepherd, 2001)

\begin{tabular}{|c|c|c|}
\hline Operações e planos & $\begin{array}{l}\text { Descrição } \\
\text { continua? }\end{array}$ & Notas \\
\hline $\begin{array}{l}0 \text { Enviar email } \\
\text { Plano } 0: 1-3-2-4 . \text { Se quiser enviar arquivo }-5 \text {. } \\
1 \text { Criar nova mensagem } \\
2 \text { Verificar vírus } \\
3 \text { Endereçar mensagem } \\
4 \text { Enviar mensagem } \\
5 \text { Anexar arquivo }\end{array}$ & $\begin{array}{l}\text { sim } \\
\text { não } \\
\text { sim } \\
\text { não } \\
\text { sim }\end{array}$ & informar limite \\
\hline $\begin{array}{l}\text { 1 Criar nova mensagem } \\
\text { Plano } 1: 1.1 \text { ou } 1.2 \\
1.1 \text { Digitar texto na hora } \\
1.2 \text { Copiar texto de outro software }\end{array}$ & $\begin{array}{l}\text { não } \\
\text { não }\end{array}$ & permitir formatação \\
\hline $\begin{array}{l}\text { 3 Endereçar mensagem } \\
\text { Plano } 3: 3.1 \text { ou } 3.2 \\
\text { 3.1 Digitar endereço } \\
\text { 3.2 Buscar na lista de endereços }\end{array}$ & $\begin{array}{l}\text { não } \\
\text { não }\end{array}$ & $\begin{array}{l}\text { usar auto-completar } \\
\text { abrir em janela separada }\end{array}$ \\
\hline $\begin{array}{l}5 \text { Anexar arquivo } \\
\text { Plano 5: } 5.1-5.2 \\
5.1 \text { Buscar arquivo } \\
5.2 \text { Confirmar arquivo }\end{array}$ & $\begin{array}{l}\text { não } \\
\text { não }\end{array}$ & $\begin{array}{l}\text { integrar com ferramenta } \\
\text { do sistema }\end{array}$ \\
\hline
\end{tabular}

Na primeira coluna da tabela, incluem-se as operações e planos. Utilizam-se os recursos de negrito e recuos para diferenciar as informações. A segunda coluna funciona como um navegador para a tabela: sempre que a resposta à questão descrição continua for sim, significa que a subtarefa ainda necessita ser decomposta e a informação correspondente aparecerá na linha de baixo. Na terceira coluna, o analista pode acrescentar observações livres. No exemplo apresentado na tabela 1, optou-se por acrescentar alguns requisitos funcionais.

Após a descrição das três possibilidades de decomposição de tarefas, cumpre ressaltar que a opção de que modalidade utilizar fica inteiramente a cargo da preferência do analista. Como as informações constantes nos dois tipos de diagramas e na tabela são as mesmas, ambas podem ser utilizadas efetivamente para dar início a uma posterior análise da informação, análise de demandas cognitivas ou análise de erros, por exemplo. Diante do exposto, selecionamos as duas modalidades diagramáticas para avaliá-las com alunos de design, considerando tanto sua facilidade de produção quanto de utilização. O método empregado para realizar essa avaliação é descrito na próxima sessão.

\section{Método da pesquisa}

O presente estudo adota uma abordagem experimental com a manipulação de uma única variável independente: modalidade de decomposição da tarefa. Tal manipulação gerou duas condições 
experimentais: hierárquica e seqüencial. O efeito da modalidade de diagrama de decomposição da tarefa foi investigado sobre seis variáveis dependentes:

- facilidade em transferir o comportamento observado ou relato oral para o diagrama;

- facilidade em entender a lógica de modelagem e a notação;

- facilidade em construir o diagrama;

- facilidade em explicar a tarefa para outra pessoa utilizando o diagrama;

- facilidade em entender a tarefa pela leitura do diagrama;

- facilidade em definir requisitos para o design de sistemas com base no diagrama.

\section{Participantes}

Trinta estudantes de graduação e dez estudantes de pós-graduação em design participaram voluntariamente do estudo. Nenhum dos participantes possuía experiência anterior com a condução de análise da tarefa, mas vários já haviam aplicado outros métodos de usabilidade. Todos os participantes produziram e avaliaram os dois tipos de diagrama.

\section{Procedimento}

O experimento ocorreu como um exercício realizado em sala de aula pelos estudantes no contexto das disciplinas de projeto gráfico e interface homem-computador (para os estudantes de graduação em design) e interação humano-computador (para os estudantes de pós-graduação).

Inicialmente, antes da realização do experimento, a professora explicou aos estudantes como funciona o método de análise da tarefa, apresentando as diferentes abordagens no que se refere às modalidades de modelagem das atividades (hierárquica ou seqüencial), os aspectos considerados na análise (operacionais ou cognitivos), a abrangência (atividades (micro) ou atividades + ambiente (macro)) e o nível de abstração (metas e sub-metas (abstrato), artefatos utilizados (concreto)). Após a exposição inicial, os estudantes receberam uma folha-resumo com exemplos dos dois tipos de diagramas e uma breve explicação sobre como produzir cada um deles. Os estudantes consultaram a folha resumo, tiraram dúvidas e iniciaram os trabalhos.

Durante o experimento, os estudantes trabalharam em duplas. Cada um dos dois estudantes demonstrou a execução de uma tarefa ou explicou verbalmente como realiza-la enquanto o outro produziu manualmente o diagrama de decomposição da tarefa correspondente (vide figura 7). Caso houvesse dúvidas durante a construção dos diagramas, foi permitido que os estudantes consultassem a professora ou mesmo outros estudantes realizando o mesmo exercício. De forma semelhante, caso os estudantes desejassem reiniciar a construção do diagrama por considerá-lo errôneo, tal modificação também era permitida. Em resumo, todas as facilidades e possibilidades em um exercício em sala de aula estiveram disponíveis durante o experimento.

Figura 7: Exemplo de diagramas produzidos por dupla de estudantes para a tarefa de compra de livro em website de comércio eletrônico (utilizado com permissão de Luís Fernando Borges e Alexander Czajkowski)
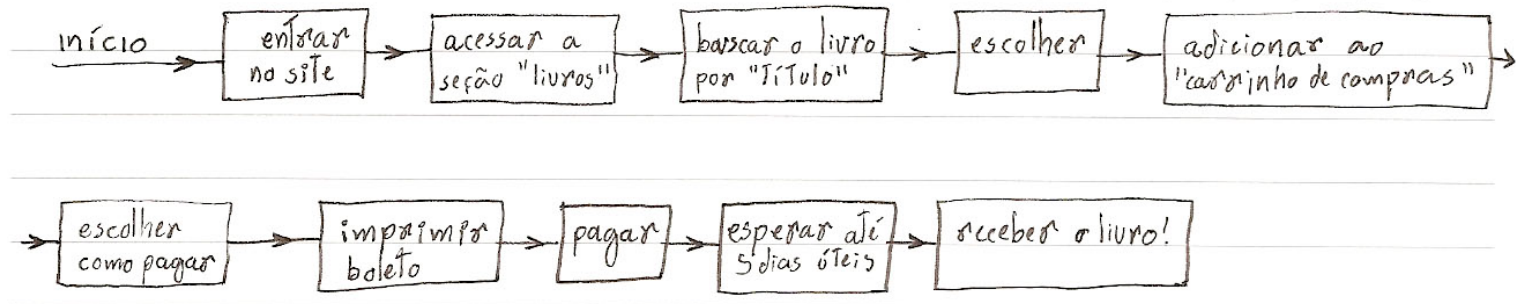


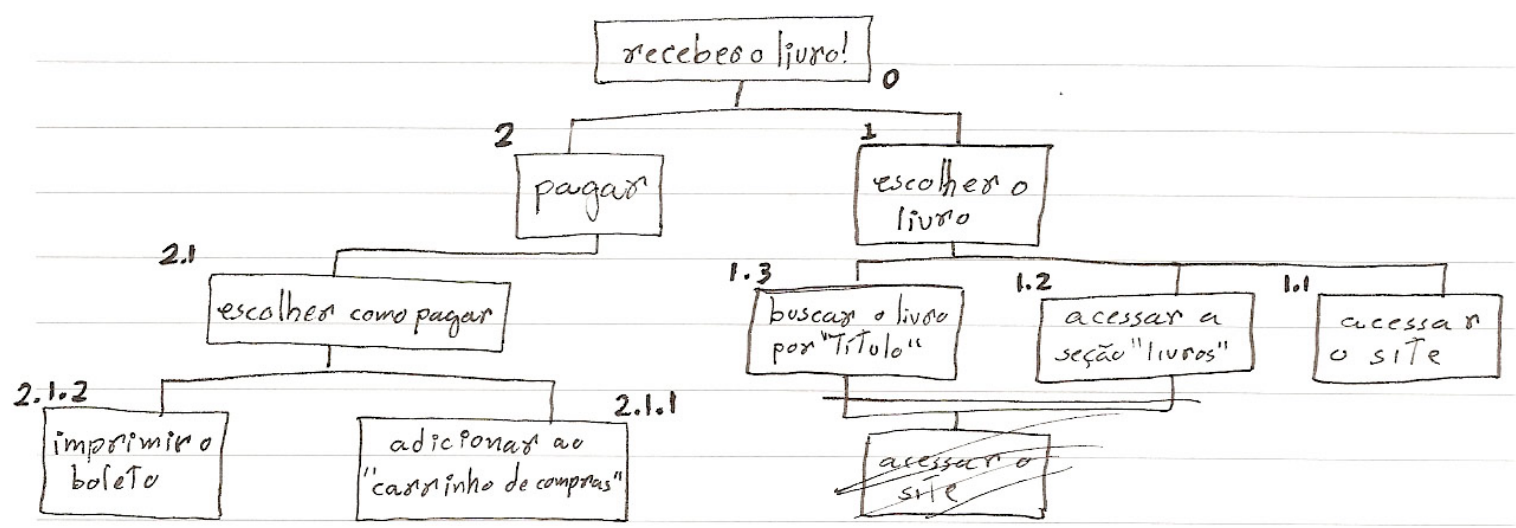

Após a construção dos quatro diagramas (dois hierárquicos e dois seqüenciais), os estudantes em dupla responderam a um questionário em que deveriam expressar sua preferência pela modalidade de diagrama de acordo com cada uma das seis variáveis dependentes. Para cada resposta, os estudantes deveriam redigir também uma justificativa. Por fim, a professora solicitou que cada dupla lesse suas respostas em voz alta, proporcionando um momento de discussão global sobre os diagramas de decomposição da tarefa.

\section{Apresentação e discussão dos resultados}

Os resultados da pesquisa revelaram uma nítida preferência dos participantes pelo diagrama de decomposição da tarefa em formato seqüencial. Esse formato de diagrama foi preferido tanto pelos estudantes de graduação quanto pelos de mestrado em todos os critérios de avaliação considerados, excetuando-se a facilidade em definir requisitos para o design de sistemas com base no diagrama. A seguir, apresentamos os resultados específicos para cada um dos critérios de avaliação, juntamente com as justificativas apresentadas pelos próprios participantes.

\section{Facilidade em transferir o comportamento observado ou relatado para o diagrama}

Todos os participantes da pesquisa preferiram o diagrama seqüencial quando consideraram a facilidade em transferir o comportamento observado ou relatado para o diagrama (vide tabela 2), sendo este o único resultado unânime em toda a pesquisa.

Tabela 2: Preferência dos participantes por tipo de diagrama (conforme a facilidade em transferir o comportamento observado ou relatado para o diagrama)

\begin{tabular}{l|l|l} 
& diagrama hierárquico & diagrama seqüencial \\
\hline estudantes de graduação & 00 & 30 \\
\hline estudantes de mestrado & 00 & 10 \\
\hline
\end{tabular}

Os principais argumentos dos participantes a favor do diagrama seqüencial foram:

- o diagrama seqüencial acompanha a descrição linear da tarefa, enquanto que o hierárquico requer que a informação seja reorganizada e categorizada;

- o diagrama seqüencial ajuda o analista a prestar atenção na tarefa enquanto está sendo observada ou relatada;

- o diagrama seqüencial é mais direto, existe uma correspondência óbvia entre o mundo real e a representação gráfica.

\section{Facilidade em entender a lógica de modelagem e a notação}

Nenhum dos participantes relatou preferência pelo diagrama hierárquico no que se refere à facilidade de entender a lógica de modelagem e a notação a ser empregada. A maioria dos participantes preferiu o diagrama seqüencial, mas uma parte não desprezível (30\%) considerou os diagramas equivalentes nesse critério (vide tabela 3 ). 
Tabela 3: Preferência dos participantes por tipo de diagrama (conforme a facilidade em entender a lógica de modelagem e a notação)

\begin{tabular}{l|l|l|l} 
& diagrama hierárquico & diagrama seqüencial & ambos \\
\hline estudantes de graduação & 00 & 22 & 08 \\
\hline estudantes de mestrado & 00 & 06 & 04 \\
\hline
\end{tabular}

O principal argumento contra o diagrama hierárquico foi que a combinação de diferentes níveis de especificidade entre as operações, aliada aos planos (para estabelecer relações entre as operações) acaba gerando confusão.

Neste critério de avaliação especificamente, é interessante considerarmos as dúvidas dos estudantes durante os estágios iniciais de produção de ambos os diagramas. As dúvidas têm início com a própria terminologia a utilizar, passando pelos conectores, numeração, redação dos planos e nível de especificidade das operações. A tabela 4 apresenta uma visão geral das dúvidas apresentadas pelos estudantes em relação aos dois tipos de diagrama.

Tabela 4: Dúvidas relacionadas à lógica de modelagem e notação nos diagramas

\begin{tabular}{|c|c|c|}
\hline & diagrama hierárquico & diagrama seqüencial \\
\hline terminologia & $\begin{array}{l}\text { O termo plano não reflete sua real } \\
\text { função no diagrama. }\end{array}$ & $\begin{array}{l}\text { Necessidade em utilizar sempre um } \\
\text { verbo e um substantivo para cada } \\
\text { operação. }\end{array}$ \\
\hline conectores & ---- & $\begin{array}{l}\text { Uso dos conectores "ou" e "e". } \\
\text { Posicionamento dos conectores em } \\
\text { relação às operações no diagrama. }\end{array}$ \\
\hline simbologia & $\begin{array}{l}\text { Dificuldade em compreender o } \\
\text { significado da barra abaixo dos } \\
\text { contêineres de algumas operações. }\end{array}$ & $\begin{array}{l}\text { Dificuldade em compreender o } \\
\text { símbolo de continuidade do } \\
\text { diagrama na linha de baixo. }\end{array}$ \\
\hline numeração & $\begin{array}{l}\text { Como numerar alternativas em } \\
\text { diferentes níveis hierárquicos. }\end{array}$ & $\begin{array}{l}\text { Como numerar atividades } \\
\text { alternativas e concomitantes. }\end{array}$ \\
\hline blocos de decisão & $\begin{array}{l}\text { Onde aparecem as tomadas de } \\
\text { decisão neste tipo de diagrama? }\end{array}$ & $\begin{array}{l}\text { Bifurcação do diagrama após um } \\
\text { bloco de decisão. } \\
\text { Uso de questão no bloco de } \\
\text { decisão ou das alternativas após a } \\
\text { questão. }\end{array}$ \\
\hline planos & $\begin{array}{l}\text { Onde posicionar os planos? } \\
\text { Como redigir os planos? }\end{array}$ & ---- \\
\hline $\begin{array}{l}\text { nível de } \\
\text { especificidade }\end{array}$ & ---- & $\begin{array}{l}\text { Necessidade de expressar todas as } \\
\text { operações no mesmo nível de } \\
\text { especificidade. }\end{array}$ \\
\hline
\end{tabular}

No diagrama hierárquico, as principais dúvidas estiveram relacionadas aos planos. A primeira dúvida diz respeito ao significado do próprio termo, o qual, segundo os participantes, não corresponde à função de relacionar as operações dentro do diagrama hierárquico. Também houve dúvidas sobre onde exatamente posicionar os planos (a regra indica que sejam posicionados a cada vez que houver uma bifurcação entre níveis hierárquicos). Os participantes também não entenderam que o diagrama hierárquico não possuía blocos de decisão e que as tomadas de decisão deveriam aparecer dentro dos planos. Por fim, tiveram dúvida sobre como redigir os 
planos, pois os mesmos utilizam texto sucinto com condicionais e conectivos (se... então...; ou ... ou ...; para ... realizar ...) à semelhança da linguagem de programação.

No diagrama seqüencial, as dúvidas foram menos pontuais do que no diagrama hierárquico. Iniciaram-se com a forma de redação das operações (se seria sempre necessário existir um verbo e um substantivo) e o nível de especificidade das operações, pois no diagrama seqüencial todas operações devem estar no mesmo nível, diferentemente do diagrama hierárquico. Também houve dúvida no uso dos conectores "ou" e "e" e seu posicionamento no diagrama, assim como no uso dos blocos de decisão e como dar continuidade ao diagrama após cada um desses blocos.

Por fim, em ambos os diagramas houve dúvidas relacionadas ao entendimento da simbologia adotada. No diagrama hierárquico, os participantes não entenderam o significado da barra colocada abaixo dos contêineres sem descrição adicional enquanto que no diagrama seqüencial o problema foi com a compreensão do símbolo de continuidade do diagrama na linha seguinte. A numeração também gerou dúvida em ambos os tipos de diagrama.

\section{Facilidade em construir o diagrama}

A maioria dos participantes considerou a construção do diagrama hierárquico mais difícil do que a do diagrama seqüencial (vide tabela 5). Os participantes argumentaram que o diagrama hierárquico seria mais complexo e que necessitaria de maior processamento mental para ser construído. Essa complexidade foi explicada pelos respondentes como uma combinação entre a não linearidade do diagrama, a necessidade de trabalhar com diferentes níveis hierárquicos e de ignorar momentaneamente a relação entre as operações para posteriormente organiza-las através de planos. A maior crítica ao diagrama hierárquico foi seu processo "não natural" de construção, conforme expressão utilizada por um dos participantes.

Tabela 5: Preferência dos participantes por tipo de diagrama (conforme a facilidade em construir o diagrama)

\begin{tabular}{l|l|l} 
& diagrama hierárquico & diagrama seqüencial \\
\hline estudantes de graduação & 02 & 28 \\
\hline estudantes de mestrado & 02 & 08 \\
\hline
\end{tabular}

Neste estágio, além das respostas dos participantes sobre a facilidade de construção dos diagramas, é interessante identificar os principais erros observados nos diagramas produzidos. No diagramas seqüenciais houve poucos erros, estando esses relacionados à não uniformidade na redação das operações (ora apenas o verbo, ora apenas o comando usado para realizar a ação, ora a página do site acessada...) e à falta de numeração. Já os diagramas hierárquicos apresentaram uma série de problemas:

- diagramas sem os planos ou com planos posicionados em local errado;

- planos escritos de forma incorreta;

- operações sem descrição adicional sem a barra inferior de indicação;

- diagramas misturando hierarquias e seqüencialidades

- diagramas seqüenciais verticais e não diagramas hierárquicos.

\section{Facilidade em explicar a tarefa para outra pessoa utilizando o diagrama}

A maioria dos participantes preferiu o diagrama seqüencial como suporte para a explicação da tarefa a uma outra pessoa (vide tabela 6). Os argumentos apresentados em favor do diagrama seqüencial foram os seguintes:

- o diagrama seqüencial pode ser utilizado como um guia, um passo-a-passo para mostrar a ordem exata em que as operações ocorrem dentro da tarefa;

- a leitura do diagrama seqüencial é mais fácil pois este segue a ordem ocidental de leitura, da esquerda para a direita, de cima para baixo. 
Alguns participantes não apresentaram uma preferência clara por um tipo específico de diagrama. A justificativa desses participantes foi de que os diagramas têm diferentes utilidades na explicação da tarefa: enquanto no diagrama seqüencial entende-se facilmente o processo de realização da tarefa, no diagrama hierárquico fica mais fácil observar a relação entre as operações em cada grupo e entre os diferentes grupos de operações.

Tabela 6: Preferência dos participantes por tipo de diagrama (conforme a facilidade em explicar a tarefa para outra pessoa utilizando o diagrama)

\begin{tabular}{l|l|l|l} 
& diagrama hierárquico & diagrama seqüencial & ambos \\
\hline estudantes de graduação & 00 & 26 & 04 \\
\hline estudantes de mestrado & 02 & 06 & 02 \\
\hline
\end{tabular}

\section{Facilidade em entender a tarefa pela leitura do diagrama}

Quando questionados sobre a partir da leitura de que diagrama seria mais fácil entender a tarefa representada, não houve unanimidade entre os participantes (vide tabela 7). A maioria dos estudantes de graduação considerou os diagramas equivalentes neste critério e, em consonância com as respostas à questão anterior, responderam que os diagramas possuem diferentes utilidades: o hierárquico ajuda a identificar relações entre funções enquanto o seqüencial auxilia no entendimento da dinâmica do processo. Também argumentaram que a facilidade de entendimento do diagrama dependeria da complexidade da tarefa que está sendo decomposta. Uma dupla citou o exemplo de uma tarefa com muitas operações alternativas ou concomitantes, o que geraria um diagrama seqüencial como uma "árvore deitada" difícil de compreender. Nesse caso, o diagrama hierárquico seria mais indicado.

Tabela 7: Preferência dos participantes por tipo de diagrama (conforme a facilidade em entender a tarefa pela leitura do diagrama)

\begin{tabular}{l|l|l|l} 
& diagrama hierárquico & diagrama seqüencial & ambos \\
\hline estudantes de graduação & 00 & 14 & 16 \\
\hline estudantes de mestrado & 02 & 06 & 02 \\
\hline
\end{tabular}

Aqueles participantes que preferiram o diagrama seqüencial apresentaram uma série de críticas ao diagrama hierárquico:

- leva-se mais tempo para entender como funciona o diagrama hierárquico, para então iniciarmos a aquisição de informação sobre a tarefa propriamente dita;

- o diagrama hierárquico demanda mais concentração pois podemos facilmente nos perder no meio de sua leitura;

- o diagrama hierárquico demanda maior tempo de observação para o entendimento.

\section{Facilidade em definir requisitos para o design de sistemas com base no diagrama}

Em contraste com os resultados em todos os critérios anteriores, a maioria dos participantes expressou preferência pelo diagrama hierárquico quando questionados sobre a facilidade em definir requisitos para o design de sistemas com base no diagrama (vide tabela 8).

Tabela 8: Preferência dos participantes por tipo de diagrama (conforme a facilidade em definir requisitos para o design de sistemas com base no diagrama)

\begin{tabular}{l|l|l|l} 
& diagrama hierárquico & diagrama seqüencial & ambos \\
\hline estudantes de graduação & 24 & 02 & 04 \\
\hline estudantes de mestrado & 08 & 02 & 00 \\
\hline
\end{tabular}


Os principais argumentos dos participantes a favor do diagrama hierárquico foram os seguintes:

- visualização da tarefa como um todo e das inter-relações entre funções e informações, facilitando a identificação de requisitos funcionais e informacionais;

- agrupa funções similares, à semelhança de um grupo de menus em um sistema;

- mostra as informações necessárias em cada grupo de funções, facilitando a estruturação do sistema.

\section{Conclusões e desdobramentos da pesquisa}

O presente estudo teve como objetivo verificar a facilidade de produção e compreensão de diagramas de análise da tarefa por estudantes de design. A partir de um estudo experimental comparando as modalidades hierárquica e seqüencial de decomposição da tarefa foi possível verificar que a maioria dos participantes preferiu o diagrama seqüencial em praticamente todos os critérios de avaliação empregados.

$\mathrm{Na}$ discussão global comparativa, realizada após o experimento, os participantes concluíram que ambos os diagramas seriam úteis durante a análise da tarefa. A escolha do diagrama dependeria do desdobramento desejado pelo analista após a decomposição da tarefa. Para uma análise de erros, por exemplo, os participantes consideraram que o diagrama seqüencial seria mais indicado, para uma análise da informação, por sua vez, o diagrama hierárquico seria mais indicado. Outra sugestão interessante foi iniciar a decomposição da tarefa com um diagrama seqüencial, para entender melhor o fluxo da tarefa e então reorganiza-lo hierarquicamente para propor uma primeira versão de arquitetura da informação para o sistema em desenvolvimento.

Como desdobramentos da presente pesquisa, vislumbram-se: (a) proposta de nova representação gráfica para análise da tarefa; (b) validação da representação gráfica proposta com estudantes de design.

\section{Referências}

ARNOWITZ, J.; FIJMA, D.; VERLINDEN, J. (2000). Communicating a task analysis with task layer maps. In Proceedings of DIS 2000. New York: ACM Press. Daabaj, 2000

KIRWAN, B.; AINSWORTH, L. K. (1993). A guide to task analysis. London: Taylor \& Francis.

MATLIN, M. W. (2004). Psicologia cognitiva. São Paulo: LTC Editora.

MILITELLO, L. G.; HUTTON, R. J. B. (1998). Applied cognitive task analysis (ACTA): a practitioner's toolkit for understanding cognitive task demands. Ergonomics, vol 41. no 11. p. 1618-1641.

NORMAN, D. A. (1993). The power of representation. In Things that make us smart: defending human attributes in the age of the machine. Cambridge: Perseus Books. P. 43-75.

RICHARDSON, J.; ORMEROD, T. C.; SHEPHERD, A. The role of task analysis in capturing requirements for interface design. Interacting with Computers, 9, 1998. p. 367-384.

SHEPHERD, A. (2001). Hierarchical task analysis. London: CRC Press. Moraes e Mont'Alvão (1998),

STUART, J., \& PENN, R. (2004). TaskArchitect: Taking the Work out of Task Analysis. In Proceedings of TAMODIA 2004. Prague: ACM Press. p. 145-154.

SUTCLIFFE, A. (1997). Task-related information analysis. International Journal of HumanComputer Studies, vol. 47. p. 223-257.

VALENTE, V. C. P. N.; Santos, E. T. (2004). Ambiente Computacional para Apoio ao Aprendizado de Geometria Descritiva. In Anais do CONAHPA 2004. p. 01-08.

\section{Sobre as autoras}

Stephania Padovani é graduada em Desenho Industrial pela ESDI-UERJ (1996), mestre em Design pela PUC-RJ (1998) e doutora em Ergonomia Cognitiva pela Loughborough University / 
Inglaterra (2001). É professora e pesquisadora do Departamento de Design e do Programa de Pós-graduação em Design da UFPR. Suas principais áreas de atuação são ergonomia da interação humano-computador, web design e design da informação, com enfoque nos temas de hipermídia, usabilidade de interfaces e métodos de design centrado no usuário. s padovani2@yahoo.co.uk

Kelli Cristine Assis Silva Smythe é graduada em Design (habilitação em Design Gráfico) pela Universidade Federal do Paraná, instituição onde também foi bolsista de Iniciação Científica pelo CNPq. Atualmente é bolsista AT (CNpq) em projeto de pesquisa sobre instruções interativas que se utilizam de animação, além de aluna especial do mestrado de design da UFPR. Seus principais temas de interesse são sustentabilidade aplicada ao design gráfico, design centrado no usuário e educação em design.

kellicas@gmail.com 